\title{
Severe Hypertriglyceridemia With New-Onset Type 1 Diabetes in Diabetic Ketoacidosis
}

\author{
Baninder Kaur Baidwan ${ }^{\mathrm{a}}$, Elizabeth T. Walsh ${ }^{\mathrm{b}, \mathrm{d}}$, Joseph A. Skelton ${ }^{\mathrm{c}}$, \\ Cathrine Constantacos ${ }^{\mathrm{b}}$, Janel D. Hunter ${ }^{\mathrm{b}}$, David F. Crudo ${ }^{\mathrm{b}}$
}

\begin{abstract}
Hypertriglyceridemia is a complication in the presentation of diabetic ketoacidosis (DKA) but has been reported in the pediatric population infrequently. We report a 13-year-old female with new onset type 1 diabetes in DKA, who developed extreme hypertriglyceridemia. Our patient's case is unique as her triglyceride levels were markedly higher than those in other reports and required a longer duration of time to resolve. We review the literature on the concomitant presentation of DKA and hypertriglyceridemia, as well as its pathophysiology and treatment.
\end{abstract}

Keywords: Hypertriglyceridemia; Type 1 diabetes; Ketoacidosis

\section{Introduction}

Elevations of triglycerides are often seen during states of insulin deficiency such as diabetic ketoacidosis (DKA). Insulin is required for lipoprotein lipase (LPL) activity that hydrolyzes and degrades triglycerides carried by chylomicrons and verylow-density lipoproteins. Mild hypertriglyceridemia is commonly seen in poorly controlled diabetes and in DKA but but severe hypertriglyceridemia with "milky" plasma rarely occurs in the pediatric population [1].

\section{Case Report}

A 13-year-old previously healthy female presented to a local hospital with a 1-month history of polydipsia and polyphagia

Manuscript submitted September 25, 2020, accepted October 10, 2020

Published online October 21, 2020

aSection of General Pediatrics, Department of Pediatrics, Wake Forest University School of Medicine, Winston-Salem, NC 27157, USA

bection of Pediatric Endocrinology, Department of Pediatrics, Wake Forest University School of Medicine, Winston-Salem, NC 27157, USA

'Section of Pediatric Gastroenterology, Department of Pediatrics, Wake Forest University School of Medicine, Winston-Salem, NC 27157, USA

${ }^{\mathrm{d} C}$ Corresponding Author: Elizabeth T. Walsh, Department of Pediatrics, Wake Forest University School of Medicine, 1 Medical Center Boulevard, WinstonSalem, NC 27157, USA. Email: etwalsh@wakehealth.edu

doi: https://doi.org/10.14740/jmc3596 and a 1-day history of fatigue, pallor, and Kussmaul breathing. Her initial blood glucose level was unobtainable due to serum appearing "milky" and the resultant turbidity interfering with the lab assay. Triglycerides were measured at $3,540 \mathrm{mg} / \mathrm{dL}$ (40.0 mmol/L). Urinalysis showed glycosuria and ketonuria. After the patient received appropriate fluid resuscitation, she was started on an insulin drip at $0.05 \mathrm{U} / \mathrm{kg} / \mathrm{h}$ and transferred to our pediatric intensive care unit (PICU) for management of DKA, severe lipemia, and concern for possible cerebral edema.

On arrival to the PICU, the patient was tachycardic (heart rate of 166), tachypneic (respiratory rate of 41) with Kussmaul breathing, and disoriented. Her capillary blood gas revealed metabolic acidosis with respiratory compensation with a $\mathrm{pH}$ 7.10, $\mathrm{pCO}_{2} 11.1 \mathrm{~mm} \mathrm{Hg}$, and $\mathrm{HCO}_{3} 3.5 \mathrm{mmol} / \mathrm{L}$. Her metabolic panel was remarkable for hyponatremia (sodium $121 \mathrm{mmol} / \mathrm{L}$, uncorrected for hyperglycemia and hyperlipidemia), hypochloremia (chloride $85 \mathrm{mmol} / \mathrm{L}$ ), acidosis (bicarbonate $6 \mathrm{mmol} / \mathrm{L}$ ) with an anion gap of $30 \mathrm{mmol} / \mathrm{L}$, hyperglycemia (glucose 533 $\mathrm{mg} / \mathrm{dL}$ ), and acute kidney injury with a blood urea nitrogen 25 $\mathrm{mg} / \mathrm{dL}$ and creatinine $1.51 \mathrm{mg} / \mathrm{dL}$. Potassium level was normal (4.5 mmol/L). Triglycerides were 7,556 mg/dL (85.4 mmol/L). Due to concern for cerebral edema, an intravenous dose of mannitol $(0.5 \mathrm{~g} / \mathrm{kg})$ was given that resulted in improvement in her neurological status. She became more alert, oriented, and interactive and quickly returned to her neurological baseline.

The patient was treated with appropriate fluid replacement and insulin infusion of $0.1 \mathrm{U} / \mathrm{kg} / \mathrm{h}$. She had an uneventful resolution of her electrolyte abnormalities and hyperglycemia and successfully transitioned to subcutaneous insulin after 24 h. Her triglyceride levels initially increased to $22,228 \mathrm{mg} / \mathrm{dL}$ $(251.2 \mathrm{mmol} / \mathrm{L})$ but then trended down to $4,876 \mathrm{mg} / \mathrm{dL}(55.1$ $\mathrm{mmol} / \mathrm{L})$. She was allowed to have a low-fat diet and her triglyceride levels rebounded to $14,443 \mathrm{mg} / \mathrm{dL}$ (163.2 $\mathrm{mmol} / \mathrm{L})$. She was noted to have scattered yellow-tinged papules on her upper and lower extremities, which were diagnosed by dermatology as eruptive xanthomas in the setting of hypertriglyceridemia (Fig. 1a, b). She was also found to have mild pancreatitis with a lipase level of $272 \mathrm{U} / \mathrm{L}$ (normal 11 - $82 \mathrm{U} / \mathrm{L}$ ). Liver transaminase levels were normal. An abdominal ultrasound revealed hepatosplenomegaly that was thought to be resulting from acute systemic metabolic abnormalities.

Due to severe and worsening hypertriglyceridemia, she was placed back on insulin and glucose infusions with restricted oral intake. Lipid-lowering treatment was started with oral fenofibrate $54 \mathrm{mg}$ daily and omega-3-acid ethyl esters 4 $\mathrm{g}$ daily. After 7 days her triglyceride level had decreased to 


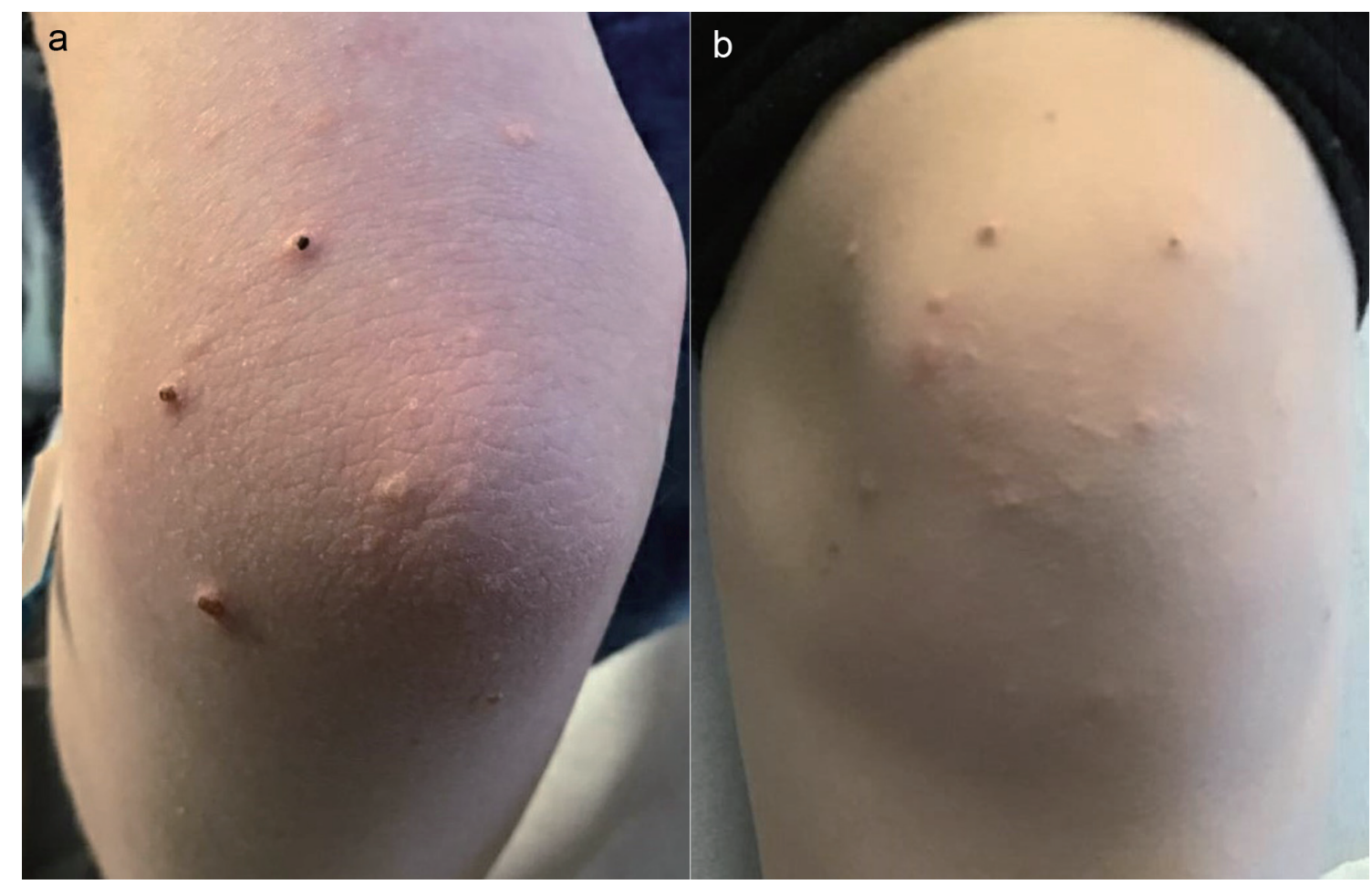

Figure 1. Eruptive xanthomas in the setting of hypertriglyceridemia. (a) Upper extremity. (b) Lower extremity.

$1,337 \mathrm{mg} / \mathrm{dL}(15.1 \mathrm{mmol} / \mathrm{L})$ and she transitioned back to subcutaneous insulin and a low-fat diet. Her triglyceride levels remained stable for 2 days on that regimen. The fenofibrate was increased to $145 \mathrm{mg}$ daily and the omega-3-acid ethyl esters were discontinued. She was discharged to home with a triglyceride level of $1,187 \mathrm{mg} / \mathrm{dL}(13.4 \mathrm{mmol} / \mathrm{L})$. Her treatment course and triglyceride levels are presented in Figure 2.

At follow-up in diabetes clinic one month later, her triglycerides were normal at $65 \mathrm{mg} / \mathrm{dL}(0.73 \mathrm{mmol} / \mathrm{L})$. She was complaining of vague musculoskeletal and abdominal discomfort intermittently and, therefore, the fenofibrate treatment was discontinued with close follow-up with a lipid specialist.

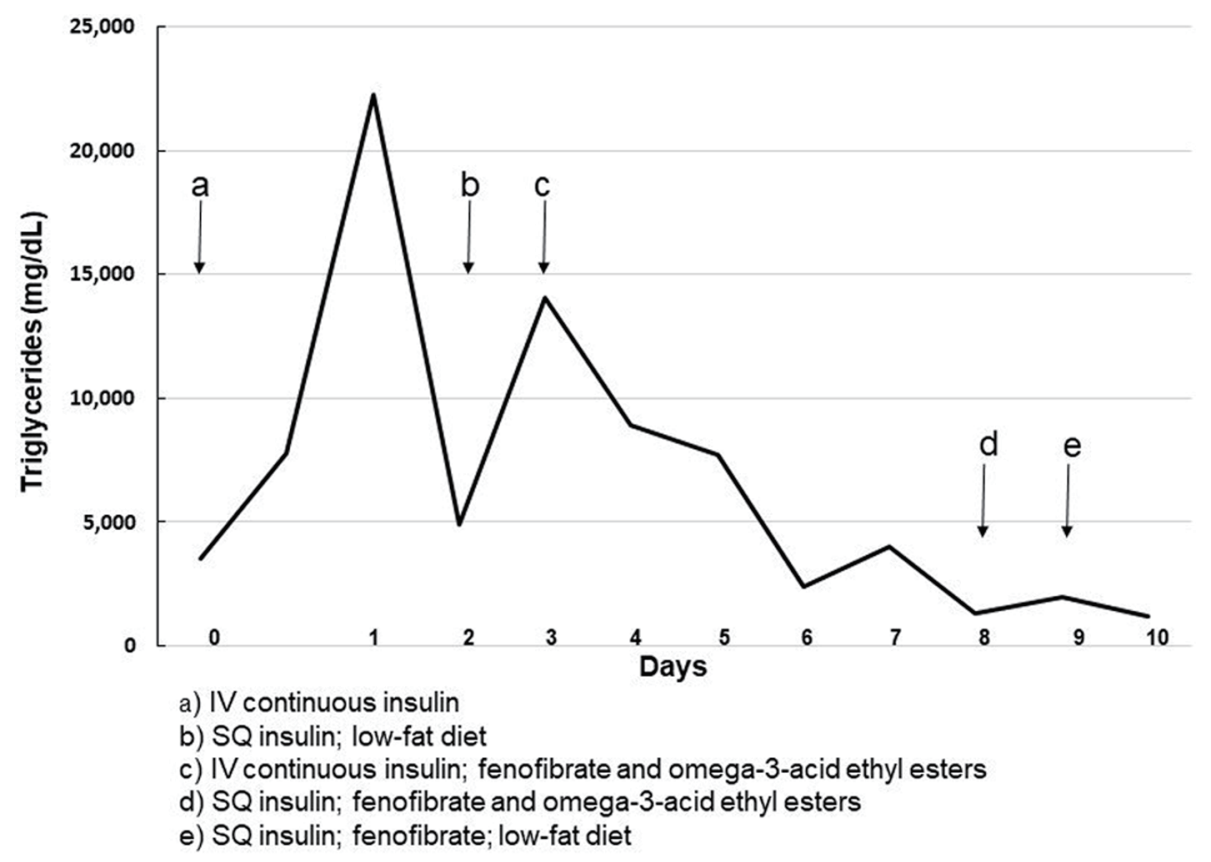

Figure 2. Treatment course and triglyceride level. 


\section{Discussion}

Hypertriglyceridemia is a rare complication in the presentation of DKA and has been reported in the pediatric population [2, 3]. Severe hypertriglyceridemia, defined as a level greater than $1,000 \mathrm{mg} / \mathrm{dL}(11.3 \mathrm{mmol} / \mathrm{L})$, has been found in $8 \%$ of the adult population with DKA, but data on the pediatric population is limited [2]. One study involving 50 pediatric patients in DKA found that $40 \%$ had hypertriglyceridemia of $>200 \mathrm{mg} / \mathrm{dL}(>$ $2.3 \mathrm{mmol} / \mathrm{L}$ ) [4]. Severe hyperlipidemia can increase the risk of pancreatitis, which has been seen in pediatric patients in DKA. Treatment of hypertriglyceridemia may include several days of intravenous insulin, and in severe cases with comorbidities or refractory cases, plasmapheresis is an option [2].

In a literature review of pediatric patients with DKA and hypertriglyceridemia, the highest triglyceride level reported was $16,334 \mathrm{mg} / \mathrm{dL}(184.6 \mathrm{mmol} / \mathrm{L})$. That patient was treated with a lipid-lowering medication and plasmapheresis with improvement of triglyceride levels to $1,100 \mathrm{mg} / \mathrm{dL}(12.4 \mathrm{mmol} / \mathrm{L})$ within 1.5 days [2]. The other reported patients were not treated with anti-lipid medication or plasmapheresis and time to normalization (triglyceride level $<500 \mathrm{mg} / \mathrm{dL},<5.6 \mathrm{mmol} / \mathrm{L}$ ) ranged from 2 - 17 days [2]. Our patient's triglyceride level of 22,228 mg/dL $(251.2 \mathrm{mmol} / \mathrm{L})$ is higher than any level previously reported in the literature. She also required a prolonged course of continuous intravenous insulin (7 days) to decrease her triglyceride levels to a level acceptable for discharge. With fenofibrate therapy and appropriate insulin therapy for her diabetes, her triglycerides normalized to $65 \mathrm{mg} / \mathrm{dL} 30$ days after discharge.

The pathophysiology of hypertriglyceridemia in DKA is understood to be related to secretion of free fatty acids from adipocytes in the setting of insulin deficiency $[2,3,5,6]$. LPL helps to clear lipoproteins which are rich in triglycerides; however, it requires insulin to function. Therefore, in insulin deficiency, LPL cannot metabolize lipoproteins and hypertriglyceridemia can occur. It has been suggested that patients with lipemic serum and significant elevations in triglycerides $(>1,495 \mathrm{mg} / \mathrm{dL}$, $>16.9 \mathrm{mmol} / \mathrm{L}$ ) be considered for further screening for lipid metabolism and structural abnormalities [7]. Our patient's family history was negative for dyslipidemia conditions, and genetic testing for disorders of lipid metabolism is being considered.

To our knowledge this is the most extreme level of hypertriglyceridemia reported in a pediatric patient in DKA. There is limited data on the effects and therapy of severe hypertriglyceridemia in pediatric DKA patients and continued research is needed.

\section{Acknowledgments}

None to declare.

\section{Financial Disclosure}

None to declare.

\section{Conflict of Interest}

The authors have no conflict of interest to declare.

\section{Informed Consent}

Parents of the patient have given their written informed consent to publish this case.

\section{Author Contributions}

All authors proved clinical care to this patient. BHB performed the literature review and wrote the initial draft. ETW, JAS, CC, JDH, and DFC collaborated in writing the manuscript, revised the paper critically for intellectual content, and approved the final version. All authors agree to be accountable for the work and to ensure that any questions relating to the accuracy and integrity of the paper are investigated and properly resolved.

\section{Data Availability}

Any inquiries regarding supporting data availability of this study should be directed to the corresponding author.

\section{References}

1. Nyamugunduru G, Roper H. A difficult case. Childhood onset insulin dependent diabetes presenting with severe hyperlipidaemia. BMJ. 1997;314(7073):62-65.

2. Saengkaew T, Sahakitrungruang $T$, Wacharasindhu $\mathrm{S}$, Supornsilchai V. DKA with severe hypertriglyceridemia and cerebral edema in an adolescent boy: a case study and review of the literature. Case Rep Endocrinol. 2016;2016:7515721.

3. Fick T, Jack J, Pyle-Eilola AL, Henry RK. Severe hypertriglyceridemia at new onset type 1 diabetes mellitus. J Pediatr Endocrinol Metab. 2017;30(8):893-897.

4. Haddad NG, Croffie JM, Eugster EA. Pancreatic enzyme elevations in children with diabetic ketoacidosis. J Pediatr. 2004;145(1):122-124.

5. Yagnik PJ, Desai PH, Modem VM. Hypertriglyceridemia with acute pancreatitis in pediatric diabetic ketoacidosis: a case report. Cureus. 2019;11(1):e3844.

6. Richardson T, Aslibekyan S, Ashraf AP. Clinical Characteristics and Sequelae of Severe Hypertriglyceridemia in Pediatrics. Endocr Pract. 2018;24(9):789-795.

7. Keefe C, Lawson S. ApoE isoform leading to hypertriglyceridemia in new onset type 1 diabetes. Clin Case Rep. 2018;6(7):1287-1290. 